\title{
EL ANEXO 2 DE LA ORGANIZACIÓN MUNDIAL DE COMERCIO Y LA PARTICIPACIÓN DE LOS PARTICULARES A TRAVÉS DEL AMICUS CURIAE*
}

\author{
Rodolfo CRUZ MiRAMONTES**
}

RESUMEN: El presente estudio se ocupa de la posible participación de terceros con interés en procedimientos de solución de diferencias que sin tener el carácter procesal de terceros interesados, consideren que sus intereses legítimos puedan verse afectados por la resolución definitiva que se pronuncie. Se parte de un caso concreto sustanciado en la OMC y de la presencia de una entidad privada en el caso a través del amicus curiae. Se hace una revisión de la reglamentación jurídica de dicha figura propia del common law en diversos regímenes jurídicos europeos y latinoamericanos. Por último se sugiere su incorporación a las reglas del entendimiento de solución de diferencias de la OMC.

ABSTRACT: This study is about the possible intervention of entities with a legal interest in dispute settlement procedures that without having the quality of third party considers that its legitimate interest could be affected by the final report of the DSB. The article departs from a specific case at the WTO and from the involvement of a private entity through the figure of Amicus Curiae briefs. An overview of the legal status of these briefs stemming from Common Law in different European and Latin-American legal regimes is made. Finally their incorporation into the Rules of the Dispute Settlement Understanding is suggested.

RÉSUMÉ: La suivante étude traite de la possible participation de personnes avec un intérêt dans les procédures de solution de controverses qui considèrent que ses intérêts légitimes pourront être affectés par la résolution définitive prononcée mais qui n'ont pas la qualité de tierces parties. On part d'un cas spécifique dans la OMC et de la présence d'une entité privée dans le cas à travers de l'Amicus Curiae. On fera un résumé de la figure de l'Amicus Curiae, provenant du Common Law, dans différents régimes juridiques européens et latino-américaines. Finalement on proposera son incorporation dans le mémorandum d'accord sur les règles et procédures régissant le règlement des différends.

* Artículo recibido el 2 de agosto de 2008 y aceptado para su publicación el 3 de septiembre de 2008.

** Doctor en derecho y profesor de Derecho comercial internacional en la Universidad Iberoamericana. 
SUMARIO: I. La preocupación. II. Los procedimientos no contenciosos pero sí conflictivos conforme al Anexo 2 de la OMC. III. Los intereses económicos en juego y la situación de los directamente afectados. El amicus curiae y su utilización en los procedimientos del ESD. IV. El amicus curiae en otros foros contenciosos. V. Conclusión y sugerencias.

\section{LA PREOCUPACIÓN}

El 24 de marzo de 2006 se dio a conocer públicamente el Informe de Apelación de la Organización Mundial de Comercio $^{1}$ (en adelante OMC) en el caso México medidas fiscales sobre los refrescos y otras bebidas que fue aceptado por el Órgano de Apelación (OSD) así como el informe del Grupo Especial por haber quedado firme al haberse resuelto el recurso mencionado.

En el párrafo 8o. se da cuenta que el 13 de enero el Órgano de Apelación había recibido un escrito de la Cámara Nacional de las Industrias Azucarera y Alcoholera (CNIAA) de México conteniendo un amicus curiae.

En nota a pie de página (número 2) se comenta que el representante del gobierno mexicano manifestó: "que no se opondría en caso de que el Órgano de Apelación decidiera aceptar el escrito amicus curiae". Por su parte, el gobierno estadounidense objetó el escrito "porque se había recibido en un momento tardío del procedimiento" pero que "consideraban que el Órgano de Apelación estaba facultado para aceptar el escrito". ${ }^{2}$

Como se desprende de los comentarios anteriores, las partes del caso fueron México (sic) como apelante, los Estados Unidos (sic) como apelado, Canadá (sic) y China ( $\mathrm{sic}$ ) como participantes y como terceros perjudicados las comunidades europeas, Guatemala (sic) y Japón (sic).

Siendo ésta la carátula del expediente debemos señalar que en el interior están como actores y principales interesados, por una parte, los productores de azúcar de caña agrupados en la Cámara Nacional de las Industrias Azucarera y Alcoholera (CNIAA), los productores y exporta-

1 WT/DS308/AB/R-AB-2005-10.

2 La primera frase de la expresión del gobierno estadounidense es a todas luces improcedente, pues se presentó dentro y es más, al inicio del procedimiento de apelación, por lo que era imposible legalmente haberlo hecho antes. Tan es así que dicho órgano lo admitió. 
dores de fructuosa y los usuarios principales de ambos, los fabricantes de refrescos, quienes utilizan a los productos como insumos en la elaboración de los mismos.

Todos los afectados no forman parte del gobierno mexicano, y en el caso de los ingenios expropiados por el mismo, éstos son administrados por un fideicomiso público que actúa como sujeto de carácter privado. ${ }^{3}$

\section{LOS PROCEDIMIENTOS NO CONTENCIOSOS PERO SÍ CONFLICTIVOS CONFORME AL ANEXO 2 DE LA OMC}

Siendo éste el escenario del caso legal, distinguimos con precisión dos entidades diversas, siendo la primera el foro en donde se plantea la discrepancia cuyas partes son miembros de la OMC que por definición son entes públicos, ya que sólo los Estados existentes acorde con el derecho internacional pueden ingresar a dicho organismo.

La segunda entidad se conforma de sujetos particulares cuyos intereses económicos se ven afectados y vinculados a un proceso sustanciado en un órgano ad-hoc dependiente de la OMC.

Por lo tanto, tenemos que de manera visible están los contendientes formales y de manera subyacente están los intereses reales, y esto obedece a que los primeros tienen el carácter de entes públicos, ya que conforme las reglas aplicables, que son las del "Entendimiento relativo a las normas y procedimientos por los que se rige la solución de diferencias" (ESD), no se contempla la posibilidad de que participen directamente en el proceso.

La situación es singular, pues los afectados directos no pueden actuar en el proceso, y los que participan carecen de interés y motivación directa en el caso, y solamente operan cumpliendo con una función burocrática.

No desconocemos desde luego la posibilidad de que los particulares presenten memoranda a sus gobiernos, formulen opiniones y aun sean consultados directamente, dependiendo de la cabida que los gobiernos les den a sus ciudadanos, pero nunca podrán apersonarse directamente en juicio.

3 Recordemos que los gobiernos pueden llevar a cabo tareas propias de un particular denominándose como acciones jure gestionis; véase mi estudio La ley norteamericana de inmunidad del Estado soberano de 1976, México, Instituto Mexicano de Comercio Exterior-Academia Mexicana de Arbitraje y Comercio Internacional, 1981. 
Ante esta situación, quienes hemos tenido la condición de asesores legales y abogados de empresas afectadas en casos tramitados ante la OMC, ${ }^{4}$ nos hemos planteado, al menos el autor de este trabajo, qué podemos hacer cuando consideramos que es mejor seguir una estrategia diversa a la que aparentemente se observa, o bien, alegar o enfatizar tal argumento, o por lo contrario, no plantear situaciones que más tarde se pueden utilizar en contra de nuestros intereses, etcétera.

Todo esto sin hacer de lado o desconocer que el piso en el que descansa el sistema está conformado también de elementos políticos y de compromisos y presiones de diversa índole, componentes del mosaico de la comunidad internacional, esto es, la real politic.

Ante el silencio de la ley sólo queda revisar el camino andado por quienes lo hicieron antes que nosotros, y de ahí surgió la idea de acudir directamente ante la OMC y presentar un escrito amparado bajo la figura del amicus curiae. Esto merece comentarlo detenidamente.

\section{LOS INTERESES ECONÓMICOS EN JUEGO Y LA SITUACIÓN DE LOS DIRECTAMENTE AFECTADOS. EL AMICUS CURIAE Y SU UTILIZACIÓN EN LOS PROCEDIMIENTOS DEL ESD}

Partiremos en nuestras reflexiones del hecho de que el ESD o Anexo 2 del Acuerdo de Marrakech no contempla en ninguno de sus preceptos la participación de los terceros que no tengan el carácter de partes o de terceros y sólo lo tendrán los miembros de la OMC.

Lo anterior significa que los grupos especiales que se establezcan conforme al artículo 6o. sólo considerarán a las partes y a los terceros enunciados en el artículo 10.

Ante estas disposiciones desprendemos que los afectados directamente en un proceso comercial, como son los importadores, los productores, los exportadores, así como ciertos sectores sociales en casos de daño al medio ambiente, no pueden hacer llegar a los panelistas sus argumentos ni sus preocupaciones.

4 El autor ha tenido oportunidad de participar como abogado de la Cámara Nacional de la Industria Azucarera y Alcoholera. 
El individuo, sea persona física o moral, tiene frente al derecho internacional público una relación de mediatez y sólo por excepción, como por ejemplo en el caso de violaciones a los derechos humanos o de diferencias en inversiones (capítulo XI del TLCAN, sección B), puede estar legitimado para acudir directamente ante el tribunal competente y demandar a un Estado.

Existe un desamparo procesal, si se me permite la licencia de llamar así al vacío legal, lo que orilla a que los afectados tengan que convencer a sus gobiernos de promover una acción ante la posible diferencia que surja y que se ubique en las hipótesis planteadas en dicho ESD, o bien acercarse a sus autoridades para defender la situación si fuere el caso, allegándole argumentos, sugerencias y elementos probatorios, mas no podrá, en ninguno de los dos casos, actuar directamente. ${ }^{5}$

Se ha intentado en algunas ocasiones modificar al ESD, como relataremos más adelante, pero sin éxito.

Hasta ahora la única forma irregular, sin duda, de lograr la aproximación al juicio ha sido a través de la figura procesal del ya invocado amicus curiae.

El amicus curiae es una figura jurídica de carácter procesal que ha evolucionado desde su origen ya remoto, desempeñando un papel relevante en varios sistemas jurídicos vigentes actualmente, o inclusive apareciendo furtivamente en algunos mecanismos procesales, como el ESD, por lo que merece referirnos a él para conocerlo.

Haremos una breve reseña histórica del mismo, de su transformación y de su recepción formal en el sistema jurídico inglés y en época reciente en otros sistemas ajenos al anterior, desembocando en su aparición un tanto ruidosa en el foro de la OMC.

\section{El amicus curiae y su utilización en los procedimientos} del ESD. Antecedentes remotos

La denominación de la figura procesal invocada nos precisa su origen al enunciar en latín que se trata de un incidente promovido por una

5 Umbricht, Georg C., "An 'Amicus Curiae briefs' on Amicus Curiae briefs at the WTO”, Journal of International Economic Law, vol. 4, núm. 4, diciembre de 2001, pp. 774 y 775 . 
persona amiga del tribunal o de la procuraduría de justicia en casos contenciosos.

Su propósito era ayudar al mismo a que ampliara y mejorara su información, o que conociera de alguna interpretación jurídica de las normas que fueren a ser aplicadas.

En su origen tenemos que dicho amicus era un tercero que no manifestaba ningún interés por alguna de las partes, sino sólo por los letrados, por lo que de hecho venía a ser un auxiliar del tribunal. ${ }^{6}$

Es fácil suponer que esta condición de desinterés se transformara en una actitud inclinada particularmente hacia una de las partes, pero lo que como bien lo expresa Víctor Bazan, parafraseando a Henry Abraham, "más que un amigo del tribunal, es amigo de la causa". ${ }^{7}$

Siendo su origen el derecho romano, como ya consignamos, curiosamente se asentó en la práctica inglesa y no en la románica, lo que se explica por el hecho de que durante varios siglos Inglaterra formó parte del Imperio, ya que habiendo sido conquistada por Claudio en el año 43, no sería sino hasta el año 407 cuando las tropas romanas abandonaron sus tierras.

En cuanto a su ausencia del derecho romano germánico tal vez la razón sea que el derecho civil no lo consideró, pues su origen se debe a un edicto del pretor peregrinus.

La institución permaneció vigente, pero sobrevivió pese a la presencia de usos y costumbres de diversos pueblos que poblaron las varias islas que conforman la Gran Bretaña.

En una conjunción conveniente de las prácticas normativas de los anglos, sajones, jutos y daneses, así como celtas y otros pueblos, se fue conformando el llamado derecho anglosajón.

De ahí partió el common law, que ya en el siglo XIII operaba en los tribunales de Londres.

Siguiendo el estudio de la profesora y jurista Martha Morineau el common law recogió las prácticas y usos locales, y decantó lo que había de común y así en cierta forma "codificó", de ahí su nombre de common law.

6 No sin sorna, el profesor Umbricht opina que esta romántica visión debemos tomarla cum grano salis, op. cit., nota 5, p. 778, nota 24 .

7 "El amicus curiae, enclave de derecho comparado y su reciente impulso en el derecho argentino", Revista de Derecho Tachirense, enero-diciembre de 2004-2005, p. 17. 
Al ser los tribunales mencionados de carácter real hubo que acudir o mejor dicho establecer otros mecanismos más simples, cercanos de los ciudadanos, en cuales se aplicasen normas basadas en la equidad de donde devino la llamada equity aplicándose en el Tribunal de la Cancillería creado para este efecto.

Ambos sistemas, el common law y el equity, funcionaron de manera paralela pero complementaria hasta la promulgación de las Judicature Acts entre 1873 y 1875, fusionando los tribunales que aplicaban ambos cuerpos legales y que ahora operan sumidos en la Supreme Court of Judicature. ${ }^{8}$

Así, a través de todo este proceso histórico tenemos que el recurso amicus curiae sobrevivió y caminó sólidamente hasta consolidarse en los órdenes jurídicos que se encuentran en el llamado comúnmente common law.

Junto a este orden jurídico tenemos al que llamamos derecho romano-germánico o civil law, observado fundamentalmente en los países latinos.

La figura del amicus curiae, descrita en líneas anteriores, está presente en el primer grupo, mas no en este segundo orden jurídico. No existe la figura del amicus curiae pese a que se admite la actuación de los terceros interesados, que pueden presentarse a juicio siempre y cuando acrediten un interés directo de carácter económico o jurídico. Así por ejemplo, en el caso de México el Código Federal de Procedimientos Civiles reconoce el derecho de los terceros a participar directamente en un juicio, siempre y cuando reúnan las condiciones formales que se establecen (artículos 429, 430 y 442).

Sin embargo, su concepto de los "terceros interesados" está lejos del correspondiente al de amicus curiae, por lo que se considera que es una institución propia del common law, y se acredita con el hecho de que existe en los órdenes jurídicos de países que formaron parte de la égida del derecho inglés. ${ }^{9}$

8 Una introducción al common law, México, UNAM, Instituto de Investigaciones Jurídicas, 1998, pp. 9-23. Véase, asimismo, Turac, André y Suzanne, El derecho de los Estados Unidos de América, México, UNAM, Instituto de Derecho Comparado, 1957, pp. 152-158.

9 Así en los Estados Unidos de América se ubica en la "Rule 37" (1) del Estatus de la Suprema Corte y en la "Rule 29" de la Federal Rules of Appelate Procedure; "Rule 18" de la Suprema Corte de Canadá, en la Orden IV, 1 de la Suprema Corte de India; en 
Con lo dicho, queda claro cuál es la condición de la institución jurídica en estudio.

Ahora cabe responder a la cuestión de porqué ha logrado no sólo sobrevivir sino permanecer y, por lo que ahora vemos, reverdecer en la práctica procesal, ya no sólo sajona ni particular, sino en otros sistemas y foros, incluyendo al internacional.

La respuesta a mi ver es simple y va de la mano con la misma simplicidad de la institución, ya que su sustanciación no es complicada, pero tal vez la razón más importante esté en el hecho de que llena una laguna procesal, ese vacío al que aludimos al inicio del presente estudio.

Unido a lo anterior tenemos que la globalización ha provocado, entre otros efectos, la necesidad de acudir a foros internacionales, donde dirimir controversias comerciales fundamentalmente, pero también de carácter civil, de inversión, de servicios, de protección del medio ambiente y otras más, afectándose no sólo derechos e intereses de las partes involucradas directamente en el caso concreto, sino también pueden repercutir en intereses aledaños de terceros que buscarán hacerse oír en juicio para defenderlos y precaverse de sus efectos perjudiciales.

Como bien dice el profesor Ascenso Herbé:

Le droit international n'est plus un monde clos, suspendu au-dessus des individus et des entreprises dans la pureté de rapports entre puissances souveraines... le amicus curiae est la brèche procédurale par la quelle peuvent engouffre individus, sociétés et associations lors que la qualité de partie est réserve aux Etats. ${ }^{10}$

La razón de las causas posibles mencionadas nos la proporciona los numerosos incidentes presentados en diversos casos que suman más de veinte a la fecha, septiembre de 2008, y su justificación se acredita con la variedad de temas comprendidos en los mismos. ${ }^{11}$

la "Rule 81" de la High Court de Nueva Zelanda y en Lange V. ABC (S108/116) de Australia, citado por Umbricht, Georg C., op. cit., nota 5, p. 780, nota 32.

10 "L'amicus curiae devant les juridictions internationales", Revue Générale de Droit International Public, París, 2001, p. 900. De la misma opinión son Gabrielle Marcean y Mattew Stilwell en "Practical suggestions for amicus curiae briefs before WTO adjudicarting bodies", Journal of International Economic Law, Oxford, vol. 4, núm. 1, marzo de 2001, pp. 155 y 156.

11 A guisa de ejemplos enlistaremos adicionalmente al nuestro, entre otros: US, lead bars (WT/DS138/AB/R); US, Import prohibition of certain shrimp... (WT/DS58/AB/R); 
La consideración que ha merecido el incidente comentado es muy interesante pues ha planteado diversas interrogantes, empezando por la posibilidad legal de su admisión por los grupos especiales, nombre técnico que las Reglas del ESD les dan a los paneles o tribunales ad hoc que propiamente lo son, baste referirnos a los artículos 2.1, 4.7, 6o., 7o., 8o., 11, 12 y apéndices 3,16 y demás.

Los panelistas, tanto de los mismos como del Órgano de Apelación, se han ocupado principalmente de los siguientes temas.

\section{A. La primera cuestión planteada consiste en definir} si es conveniente o no la presencia de varios participantes en un proceso que conoce de las discrepancias de miembros de la OMC

En todo acto de esta naturaleza se distinguen siempre a las partes propiamente dichas, quienes sostienen posiciones encontradas en el caso; a los terceros que alegan y acreditan tener interés legítimo en la discrepancia, y a otros que por diversos motivos les interesa acudir al mismo.

Para ser admitidos en el asunto deben tener legitimación, es decir, un estatus legal que las normas procesales aplicables les conceden.

Así, necesariamente los primeros deben acudir, pues sin ellos no habría caso. Los terceros interesados pueden aparecer y los requisitos para que lo puedan hacer son los señalados por las normas procesales aplicables.

Existen, sin embargo, otros terceros que pueden ser llamados a juicio por las partes o por la misma autoridad en razón de su pericia, información o relación con el caso.

Como desprendemos, estos terceros de segundo nivel cumplen con algún requisito particular y su presencia en el caso no es espontánea sino a petición de parte.

Sin embargo, se pueden distinguir aún otros terceros de "tercer nivel", podíamos llamarlos así, que por circunstancias muy particulares consideren que los resultados del caso pueden afectar también sus intereses, pero que carecen de legitimación para presentarse a juicio — éste se-

EC, Meausures affecting Meat and meat products (WT/DS26 48/AB/R); Estados Unidos, plomo y bismuto (WT/DS138/AB/R); CE, Sardinas (WT/DS231/AB/R); Estados Unidos, madera blanda IV (WT/DS/257/AB/R); CE, Amianto (WT/DS135/AB/R); EC, Approval and marketing of Biotech Products (WT/DSB/M/155). 
ría el término procesal pertinente - o sea para hacer oír sus inquietudes y auxiliar así a los juzgadores para que los tomen en cuenta al momento de pronunciar su fallo, laudo, opinión o informe final, cualquiera que sea la denominación que escojamos.

Estos terceros de "tercer nivel" como derivamos, están cerca del plano de los terceros-primeros, o aun pueden estar del lado de alguna de las partes, mas, procesalmente hablando, carecen de posibilidad legal de aparecer en escena.

Así las cosas, se consideró por los afectados que debían estar presentes también en el procedimiento, y que al no ser considerados en la ley, el único camino a seguir para no continuar mudos y hacer oír sus puntos de vista era a través de la figura procesal del amicus curiae. La primera ocasión en que se utilizó el amicus curiae ante la OMC fue en 1998, ${ }^{12}$ provocando el planteamiento de fondo al que aludimos líneas arriba.

B. Otra cuestión de fondo es definir si existe base legal para que los amici deban ser aceptados por los Grupos Especiales o por el Órgano de Apelación

De la respuesta que se dé, se derivará la obligación de tomarlos en cuenta al momento de pronunciar el informe final, o bien de utilizar sólo lo que estimen pertinente, o inclusive de rechazarlos por improcedentes.

En caso de que se considere que no hay impedimento legal para aceptar dichos incidentes surgen las siguientes cuestiones:

- ¿Pueden presentarse solamente ante los grupos especiales, o nada más ante el Órgano de Apelación, o bien indistintamente?

- ¿Los amici producen algún efecto jurídico?

- ¿Se requieren algunos requisitos formales para su presentación?

- ¿Debe el interesado recabar del destinatario del recurso autorización previa?

- Quienes presentan los incidentes ¿deben ser las ONG necesariamente, o puede ser cualquier interesado incluyendo a un miembro que no tenga el estatus de tercero?

12 EC-Meausures Affecting Meat and Meat Products WT/DS26 y 48/AB/R/ 13-II-1998. 
Del análisis que hemos efectuado podemos derivar las respuestas a ésta y otras cuestiones, como veremos a continuación.

Para conocerlas revisaré, adicionalmente a los estudios ya citados, algunos otros, así como documentos de la misma OMC cuando sea pertinente.

Dichos estudios, como el presente, han recogido las opiniones directas de los panelistas miembros de los grupos especiales y del Órgano de Apelación, quienes han tenido la principal tarea que les concierne, pues son los que se verán afectados en la sustanciación de los casos por la introducción de los amici y de despejar las dudas que acarrean.

Como es entendible, los primeros casos en los que se planteó el amicus curiae lidiaron con los temas de fondo y los siguientes, sin perjuicio de abundar en las respuestas dadas de los asuntos procesales o adjetivos.

Hay algunos casos que devienen definitivos para conocer los criterios aceptados hoy en día. ${ }^{13}$

A) Una primera respuesta que podemos encontrar es que los paneles que se han ocupado de precisar si es legalmente posible aceptar los incidentes mencionados, se han ido por la afirmativa, pese a que existe también una fuerte oposición a permitir que terceros carentes de legitimación se monten al foro.

Sin embargo, y de ahí parte nuestra aseveración, el Órgano de Apelación se pronunció francamente en este sentido en el caso que pasó a ser clásico en el tema de: "Comunidades europeas. Medidas que afectan al amianto y a los productos que contienen amianto". ${ }^{14}$

En dicho documento se hace saber al Órgano de Solución de Diferencias que, "en interés de la equidad y el orden de las actuaciones en el procedimiento", se decidió adoptar un procedimiento adicional para tramitar cualquier ocurso que reciba de personas que no sean partes ni terceros en la diferencia.

Se enfatiza que dicho procedimiento sólo se aplicará al caso en cuestión o sea EC-amianto y por lo tanto "no constituye un nuevo procedimiento de trabajo establecido... con arreglo al párrafo 9 del artículo 17

13 US/Import prohibition of certain shrimp and shrimp products (shrimp turtle), WT/DS58/AB/R,1998; US/Imposition of countervailing duties on certain Hot rolled lead, WT/DS138/AB/R, 7 de junio de 2000 (Carbon Steel).

14 WT/DS135/9, 8 de noviembre de 2000. 
del Entendimiento relativo a las normas y procedimientos por las que se rige las solución de diferencias" (ESD).

Se invocó como fundamento legal el párrafo 1 de la regla 16 de los "Procedimientos de trabajo para el examen en apelación".

El Consejo General, poco después, dio a conocer que el Órgano de Solución de Diferencias en su reunión inmediata a recibir dicho comunicado había adoptado la posición del Órgano de Apelación citada y del grupo especial, en su sesión del 22 de noviembre de $2000 .{ }^{15}$

B) Entresacamos del documento anexo al comunicado oficial los siguientes puntos:

a) Que cualquier persona que no sea parte o tercero en el procedimiento "EC-asbestos"... y desee presentar un escrito al Órgano de Apelación, deberá solicitar su autorización.

b) Se enlistan siete requisitos adicionales, entre los cuales está la identificación del firmante del escrito, la razón de su interés, la justificación de por qué el Órgano de Apelación deberá aceptar su escrito y tomar en cuenta sus razones y argumentos, y si existe una relación directa con algunas de las partes o del tercero.

Todo esto deberá expresarse en un escrito que no exceda de tres páginas mecanografiadas. Si se le concede la autorización pedida, el oferente limitará su escrito a un documento no mayor a veinte páginas incluyendo los fundamentos de derecho. De dicho escrito se correrá traslado a las partes y a los terceros si los hubiese, para que en un término perentorio se pronuncien sobre el mismo si así lo desean hacer.

Así, conforme a lo expresado, se acepta que el amicus curiae puede admitirse por el Órgano de Apelación pero no existe obligación legal de hacerlo, ni menos de tomar en cuenta los argumentos e información que contenga. En cuanto al requisito de solicitar la autorización para presentarlo se ha dejado de lado.

Por lo que toca a los demás requisitos que comentamos, han servido para los incidentes posteriores, al no haber un acuerdo expreso del órgano de solución de diferencias. En el caso de nuestro amicus curiae nos atuvimos a la guía antes dicha. 


\section{Dado lo anterior, ¿cuál es la naturaleza jurídica del amicus curiae?}

El énfasis dado por los órganos de la OMC aludidos a la limitación de las normas procesales consignadas a que solamente se apliquen al caso examinado, "EC-asbestos", encierra una cuestión que exige un cuidadoso examen.

En efecto, la posibilidad de interponer el incidente ¿parte de un "derecho" en un sentido laxo, del tercero de "tercer nivel" como lo hemos calificado o constituye un mero paso tolerado generosamente para abrir la puerta a dicho interesado?

Se han invocado varios preceptos para fundamentar los amici, tales como el artículo 13 del ESD que se refieren al derecho de los grupos especiales para recabar información, así como a los artículos 17.9 del ESD y 16.1 del apéndice 3 de éste, que contienen los Procedimientos de trabajo de los mismos.

Dichos procedimientos son básicamente los mismos pues, el artículo 13 expresamente nos indica que: "cada grupo especial tendrá el derecho de recabar información" (énfasis añadido).

Por su parte, el artículo 17.9 señala: “9. El Órgano de Apelación... establecerá los procedimientos de trabajo" y dichos procedimientos de trabajo son los contenidos en el apéndice 3 ya citado.

A los anteriores preceptos debemos agregar el artículo 12, que en su párrafo primero confirma lo dicho sobre la cobertura del apéndice 3 .

Resulta evidente la preocupación de la OMC por fortalecer y facilitar la tarea de los grupos encargados de buscar soluciones a los posibles o presentes conflictos inter-partes, de ahí que su función sea como la de todo juzgador: conocer primeramente los hechos que rodean al caso con la mayor precisión posible para evaluarlos en toda su dimensión y de ahí pronunciarse justamente.

Por ello, es propio a los juzgadores allegarse toda la información, elementos de convicción y demás para cumplir a cabalidad con lo preceptuado en el artículo 11 del ESD, que determina cuáles son las funciones de los grupos especiales, y con el artículo 17.6 que encierra el objeto de la apelación.

Aceptado lo anterior, cabrá como en todo proceso, sea en primera o en segunda instancia, la presencia del amicus curiae. 
Estimamos que esta argumentación es sólida y parte del mismo propósito esencial de la OMC y de las finalidades del GATT, pues propone una explicación en plena congruencia con todos los acuerdos que conforman el enramado de los tratados multilaterales y plurilaterales de la misma.

Observamos de la misma que la razón que explica al amicus curiae descansa en una facultad discrecional del juzgador, nada más dice en relación con quien presenta dicho recurso.

Para conocer la respuesta debemos aludir a la naturaleza jurídica del amicus curiae.

Todo proceso legal debe comprender un mínimo de garantías que parte de la esencia del ser humano, como son: enterarse oportunamente de la existencia de un acción en su contra, tener la posibilidad de defenderse y oponer los argumentos y presentar las pruebas que le favorezcan $\mathrm{y}$, en fin, contar con un mínimo de facultades resumidas y consagradas en los términos de "audiencia y legalidad".

Dado el proceso mundial de la globalización en que estamos inmersos, se están presentando fenómenos derivados de acciones económicas y financieras que afectan seriamente a quienes no son partes en el juicio, sin que puedan tomar medidas para su protección.

Esto es, que el ejercicio de un interés particular para obtener resultados económicos favorables, casi siempre de lucro, puede acarrear daños graves a particulares, grupos sociales determinados o inclusive no determinados, como puede suceder en el caso de contaminación de la naturaleza.

Se puede alegar que en estos casos existe una facultad implícita en los afectados relativos del derecho que pudiere alegar quien lleva a cabo dichas acciones fundadas en su libertad de trabajo, pero que no riñe con su obligación de evitar los efectos dañinos y perjudiciales.

En cambio, nada se ha dicho sobre la posibilidad de que los terceros de tercer nivel puedan presentarse a juicio.

Hasta ahora, tal como hemos visto, no existe en el ámbito del derecho procesal internacional una figura jurídica que abra los procedimientos contenciosos al posible afectado para que haga valer sus derechos.

Aquí es donde aparece la institución objeto de nuestro estudio.

Por lo argumentado tenemos que la posibilidad de acudir al amicus curiae se funda en la existencia de un derecho subjetivo de quien considere que puede aportar algo en ayuda del juzgador en su tarea, sin im- 
portar si es persona física o moral, $\mathrm{ONG}$ o un experto en la materia de que trate. ${ }^{16}$

Será por intermedio de dicha figura procesal que el interesado tenga la capacidad de ejercer un derecho a estar, sin ser parte, en un procedimiento en el que no solamente auxilie al panel, sino también defienda lo que le parezca pertinente y de paso apoye a alguna de las partes.

La actitud, observada hasta ahora, del Órgano de Apelación que hemos comentado constituye, a mi parecer, el reconocimiento implícito de la existencia del derecho a favor de quien se presenta a juicio mediante el amicus curiae, por lo que no es, como pudiere pensarse, un acto de mera cortesía o una respuesta generosa.

De paso comentamos que en las ocasiones en que se han presentado dichos incidentes no se ha limitado el número de participantes, y así tenemos, por ejemplo, que en el caso "EC-Asbestos" acudieron 17, y en otros solamente 1, como el de "México-medidas fiscales", ${ }^{17}$ que es el nuestro.

Cabe ahora establecer, frente a dicha facultad, quién tiene el deber jurídico de satisfacerla, y nuestra respuesta está en que será precisamente el órgano que conozca del conflicto comercial en la OMC.

El jurista C. Wilfred Jenks sostiene que el derecho internacional público actual ha evolucionado y lo sigue haciendo para comprender las nuevas situaciones que los avances tecnológicos, científicos y sociales, y el propio desarrollo general de la humanidad va logrando, y desde luego incluye a las instituciones que se establecen como resultado de dichos avances.

Por lo tanto, abarca, entre otros, a los derechos de propiedad con carácter específicamente internacional, al derecho de la interdependencia económica y, particularmente para nuestro interés, la protección interna-

16 El concepto de derecho subjetivo al que nos referimos, es el que define el maestro Óscar Morineau derivado del análisis que realiza sobre diversas opiniones de grandes juristas como son Kelsen, Ihering y otros. Nos unimos a las afirmaciones siguientes: "tratándose de los derechos llamados garantías individuales, la norma otorga facultades a los hombres en general e impone deberes correlativos a todo el mundo". "El derecho subjetivo es una fusión del facultamiento de conducta hecho al titular... y de la facultad de exigir el cumplimiento del deber correlativo"; "un derecho subjetivo no depende de la voluntad del sujeto", véase El estudio del derecho, México, Porrúa-UNAM, 1997, pp. 111, $120,121-134$.

$17 \mathrm{AB} / 2005 / 10$. 
cional de los derechos humanos, en donde se ubican junto a las libertades civiles, los derechos económicos y sociales. ${ }^{18}$

Lo anterior fortalece nuestra explicación de que frente a todo derecho subjetivo existe una obligación correspondiente a cargo de un tercero, acorde con la bipolaridad de toda norma jurídica, y así el tercero señalado podrá ejercer su derecho de audiencia a través del amicus curiae y será el juzgador quien deberá permitir el ejercicio de la susodicha facultad.

Existe, de conformidad con lo señalado, un derecho común de la humanidad, de la communitas communitatum, o dicho en otras palabras, una especie de common law universal que asegura el ejercicio de los derechos de todo proceso legal.

Siendo así, no faltará quien pregunte ¿y porqué no se incluyó en el texto del ESD?

Tal vez, si es que se pensó en el amicus curiae al negociarse su texto, se estimó dejarlo para más adelante cuando los acontecimientos lo reclamasen.

O mejor aún, como lo consideramos nosotros, no se pensó en ello por constituir un elemento de menor relevancia que los temas atendidos en los preceptos del ESD, y más aún cuando se trata de una institución que sólo es conocida y practicada en donde se aplica el common law.

Cualquier explicación que aceptamos será válida; lo que importa es que su presencia no solamente no choca ni contradice los propósitos del ESD sino que apoya sus funciones.

\section{Aceptado que así suceda, será necesario precisar los efectos de su presentación}

Hasta ahora se ha establecido que no generan la obligación legal de que los miembros del cuerpo colegiado juzgador los tomen en cuenta en sus informes finales.

Esto significa que los panelistas disponen de una discrecionalidad procesal para considerarlos en su totalidad, parcialmente o simplemente dar cuenta y fe de que fueron presentados.

18 Pérez González, Manuel, "El derecho común de la humanidad”, Revista Española de Derecho Internacional, Madrid, año XXII, núm. 2, 1969, pp. 385-389. 
Generalmente se ha dicho, en la mayor parte de los casos, que los amici no han añadido nada nuevo o no han ayudado a los panelistas.

En nuestro caso se dijo que no resultaba "necesario" tomar en cuenta el amicus curiae presentado.

Hasta ahora, según parece, ningún amicus curiae ha merecido ser tomado en cuenta al momento de elaborar el informe final.

E. ¿Qué sucede si un miembro de la OMC que pudo ser parte o tercero en un caso y no lo fue, decida hacerse presente mediante el amicus curiae?

Cabe añadir al tema de la calidad o condición de los terceros de "tercer nivel", como los he calificado, que no existiendo ningún requisito sobre los sujetos en cuestión, sí cabría considerar la pregunta de nuestro subtítulo.

Existe ya un caso concreto, y ante la situación original del asunto, el Órgano de Apelación sostuvo que teniendo la potestad para recibir amicus curiae de personas particulares o de organizaciones, estaba facultado con mayor razón para aceptar que procediese de un miembro y asimismo no estaba obligado per se para tomarlo en cuenta. ${ }^{19}$

De esta forma contundente quedó reafirmada la facultad del Órgano de Apelación para dar cabida a los amici de los miembros.

Adentrándonos en otras cuestiones, nos detendremos en el asunto de los temas que han provocado la presencia de los amici.

\section{La protección al medio ambiente ha provocado numerosas}

reacciones de terceros quienes han acudido vía amicus curiae a los procedimientos contenciosos de la OMC

Además del caso "EC-Asbestos", se han sustanciado otros de notable importancia por su actualidad como es el de "EC-Approval and marketing of biotech product", ${ }^{20}$ en el cual fueron parte los Estados Unidos de América, Canadá y Argentina por una parte, y por otra las Comunidades Europeas.

La trascendencia del tema atrajo de tal manera la atención, al grado que se integraron dos grupos de participantes vía amicus curiae, uno

19 Appelate Body Report, EC-Sardines, WT/DS231/AB/R, pp. 164, 165 y 167.

$20 \mathrm{WT} / \mathrm{DSB} / \mathrm{M} / 155,2003$. 
constituido por cinco personas presentes en su calidad de expertos en el tema y en ciencias sociales.

El otro grupo se denomina Amicus Coalition, conformado por quince instituciones no gubernamentales.

No siendo el propósito del presente estudio abundar en los casos resueltos o en trámites atraídos por el objeto de nuestras consideraciones del momento, remitimos a quien le motive el "Biotech case", como se le llama al estudio de la colega neocelandesa Caroline F. Foster ${ }^{21}$ del que derivamos estas notas.

$A$. En este orden de temas conexos, que giran alrededor del amicus curiae y su discusión, cabe mencionar posiciones tomadas en algunos casos pasados, de las partes en el que origina este estudio: Estados Unidos y México.

Desde luego, sólo haré una breve referencia desprendida de nuestro caso ante el hecho de que México, parte en el caso, no se opuso al amicus curiae que promovimos y el gobierno estadounidense sí ¿cuál ha sido la posición de ambos países en el pasado?

Para conocerla nos referiremos a uno de los asuntos que ha considerado el tema y las aristas del amicus curiae, como fue el denominado como "US-Carbon Steel"22 ya invocado.

Habiéndose presentado dos comunicados, por la "American Iron and Steel Institute" y por la "Speciality Steel Industry of North America", fueron impugnados por las Comunidades Europeas considerando que eran inadmisibles.

El Órgano de Apelación se dirigió el 16 de febrero de 2000 a los gobiernos de los Estados Unidos, de Brasil y de México, solicitando comentaran la posición de las Comunidades Europeas.

Tanto Brasil como México apoyaron los argumentos y la petición de las Comunidades Europeas en su carácter de terceros, conforme al artículo 10 del ESD.

21 "Social Science experts and amicus curiae brief in international courts and tribunals: The WTO Biotech case", Netherlands International Law Review, The Netherlands Issue, The Hague, 2005, pp. 435, 436 y 440.

22 "Imposition of countervailing Duties on Carbon Steel Products origination in the United Kingdom", conocido como Carbon Steel Dispute, WT/DS138/AB/R. 
En cambio, los Estados Unidos sostuvieron lo contrario, en el sentido de que el Órgano de Apelación tiene las facultades legales para aceparlo con base en el artículo 17.9 del ESD. ${ }^{23}$

Habiéndose vertido argumentos sólidos y por demás interesantes en ambos sentidos, encontramos que a la fecha han prevalecido los que apoyan la existencia de bases legales en el ESD para que los paneles admitan los amici con las limitaciones y consideraciones que ya hemos apuntado.

Dicho esto, tenemos que en nuestro caso particular el gobierno mexicano no se opuso afortunadamente al amicus curiae que presentamos, y el gobierno estadounidense lo rechazó por motivos fútiles, mas no negó la facultad legal del Órgano de Apelación para recibirlo y comentarlo. Es un hecho que estimamos interesante comentar por su importancia futura.

Si bien es cierto que en pocos años se han dado respuestas válidas al amicus curiae en la OMC y a las cuestiones que ha planteado, el asunto no ha quedado resuelto a satisfacción.

$B$. Hay una seria inquietud consistente en que no resulta congruente el hecho de que hasta ahora todo el juego ha estado en los paneles de la OMC, particularmente en el Órgano de Apelación, mas no en el Consejo General, quien debe tomar las decisiones que corresponden dejando firmes y sólidas las resoluciones del mismo.

Los analistas del tema han expresado opiniones muy valiosas que fortalecen las decisiones en cuestión, así como señalado algunos inconvenientes, que unidos a las reflexiones de los panelistas de los casos pertinentes constituyen un cuerpo doctrinario importante. ${ }^{24}$

Tal como dice elegantemente el jurista italiano Roberto Baratta: "Anche sotto questo profilo, ricorre l'esigenza che la participazione dell'amicus si ponga un assoluta sintonia con le regole imposte dal 'DSU'”. 25

23 Véase los párrafos 36 y 37 del Informe Final del caso mencionado y el artículo analítico del profesor Arthur S. Appleton: "Another Rabbit from the Appellate Body?", así como los comentarios de los editores, en Journal of International Economic Law, vol. 13, núm. 4, diciembre de 2000.

24 A los trabajos de Georg C. Umbrich ya apuntados, se unen adicionalmente a los de Marco C. E. F. Bronckers y John H. Jackson, Peter D. Ehremhaft, American Bar Association, Geert A. Zonnekexn, Herbert Jacob, que hemos utilizado, sin perjuicio de otros más que se han producido a la fecha.

25 "La legitimazione dell' amicus curiae dinanzi agli organi juidizali della organizzazione mondiale dell commercio", Rivista di Diritto Internazionale, Milán, vol. XXXV, fasc. 3, 2002. 
Este tema pendiente de atender y otros más pueden ser víctimas inesperados del impasse derivado de la imposibilidad de culminar con la Ronda Doha.

Por las razones ya aludidas, estimamos que no será en un plazo cierto que se consolide formalmente la figura procesal en un texto del ESD y que se continúe acudiendo a la licencia admitida por el Órgano de Apelación, en la forma en que actualmente se hace.

Este tema se añade a otros sin resolver que están en la "lista", como es el caso de si debe iniciarse el proceso de revisión a que se refiere el artículo 21.5 para establecer el panel de vigilancia con las consultas o saltarse este paso. Del tema me he ocupado ya con motivo de otro caso en el que también participé. ${ }^{26}$

En la sección siguiente mencionaremos muy brevemente, por salirse del tema central de nuestra indagatoria, los otros foros distintos a la $\mathrm{OMC}$, en donde también se recurre al amicus curiae para fines similares a lo que se persigue en los procedimientos aludidos de carácter comercial.

\section{EL AMICUS CURIAE EN OTROS FOROS CONTENCIOSOS}

Podemos señalar que con excepción del foro estadounidense y tal vez de aquéllos regidos o inspirados en el common law, durante los últimos quince años han aparecido casos litigiosos en los que el amicus curiae ha estado presente, o bien lo que resulta más notable, se ha incorporado formalmente a los códigos procesales nacionales delimitando sus alcances legales.

Tal es el caso que nos presenta el abogado Yves Laurin, en una revisión por demás ilustrativa del amicus curiae en Francia.

Considera de inicio que la institución, como la califica, es de origen "pretoriano" y que se ha ido desarrollando en la práctica judicial, concretamente se aplica en los casos de moratorias.

Habiéndose admitido por el Tribunal de Apelación de París, mediante Decreto del 21 de junio de 1988, constituye una forma de allegarse información, mediante una invitación del tribunal para "proporcionar en

26 Cruz Miramontes, Rodolfo, "Las controversias comerciales en el marco de la Organización Mundial de Comercio", en Drnas de Clément, Zlata (coord.), Estudios de derecho internacional en homenaje al profesor Ernesto Rey Caro, t. II: El panel de vigilancia, pp. 1132-1143. 
presencia de todas las partes interesadas, información pertinente a los jueces que les auxilie en sus investigaciones para resolver el litigio" (traducción personal del original en francés). ${ }^{27}$

La práctica de esta institución, sin embargo, es anterior a la fecha de su incorporación al Código Procesal Civil, y nos lleva según el abogado Laurin al ámbito universitario al solicitar los juzgadores opiniones calificadas, sobre todo en el campo de la ética en debates sobre la pena de muerte y más recientemente en casos de crímenes contra la humanidad.

Curiosamente también se utiliza en otro campo de acción aparentemente bien distinto - ¿o no lo será tanto? - como es el financiero y de las operaciones de Bolsa.

Esta práctica procesal se da fundamentalmente en el foro, con el propósito de que terceros al caso concreto, principalmente abogados, sean invitados a cumplir con esta tarea de apoyo y auxilio a la autoridad.

El ámbito de aplicación del amicus curiae al campo financiero, sobre todo al que corresponde al de inversiones internacionales, se ha incrementado a tal grado que ha provocado que el Centro Internacional de Arreglo de Diferencias (CIADI), ${ }^{28}$ haya modificado su Reglamento de arbitraje incorporándolo en la regla 37 (2) el 10 de abril de 2006. Por su actualidad y su originalidad cito su texto a continuación: “(2) Después de consultar a ambas partes el Tribunal puede permitir a una persona o entidad que no sea parte en la diferencia (en esta regla parte no contendiente), que efectúe una presentación escrita ante el Tribunal, relativa a cuestiones dentro del ámbito de la deferencia". ${ }^{29}$

De su lectura desprendemos:

a) Que la presencia mediante el amicus curiae será posible, previa aceptación de ambas partes, esto es, se requiere su autorización.

b) Que la parte no contendiente "tiene un interés significativo en el procedimiento".

27 'L'Introduccion de la notion de personne qualifié (amicus curiae) dans le code de procedure cuvit", Recueil Dalloz, núm. 36, 15 de octubre de 1998, p. 1.

28 El CIADI es una entidad muy especializada creada mediante un acuerdo internacional el 18 de marzo de 1965 bajo los auspicios del Banco Mundial, conociéndose dicho acuerdo como el "Convenio de Washington". Véase Rodríguez Jiménez, Sonia, El sistema arbitral del CIADI, México, Porrúa-UNAM-UIA, 2006.

29 Tomada de "Latin America Investment and Arbitration Law", Bi-Monthly, Ignacio Gómez Palacio, 15 de marzo de 2007. 
c) Que la información que se proporcione aportará “una perspectiva, en conocimiento o una visión particulares, distintos a aquellos de las partes en la diferencia".

d) Que al no especificar, el tercero podría ser invitado por el tribunal o presentarse de motu propio.

Por ello, en nuestra opinión podrá asimilarse a la figura del tercero interesado y no constituir otro personaje distinto como sucede según lo consideramos al analizar el amicus curiae en la OMC.

Para la confirmación de la naturaleza jurídica del mismo, o sea de la "parte no contendiente", como la llama el precepto citado, se invocan dos resoluciones de sendos Tribunales en casos CIADI que resuelven puntos de los procedimientos en que expresamente se refieren a los amicus curiae. Dichos caos son:

1) Aguas Providenciales del Santa Fe S. A. Suez, Sociedad General de Agua de Barcelona S. A. e Inter-aguas Servicios Integrales del Agua S. A. vs. La República Argentina, Caso CIADI No. ARB/03/17.

2) Suez, Sociedad General de Agua de Barcelona S. A. y Vivendi Universal S. A. vs. La República Argentina-Caso CIADI No. ARB/19.

Ambos casos son muy recientes, pues el primero es de 2006 y el segundo de 2007.

Podemos añadir a lo anterior que dicha institución procesal está presente también en otros campos jurídicos, como son el de los derechos humanos involucrando al penal y al constitucional.

Mencionaré sobre lo primero un caso que aparentemente ha sido pionero en la República Argentina, pues se remota al año de 1995 (18 de mayo), al pronunciarse una resolución dictada por el Tribunal que conocía la causa núm. 761. "Hecho denunciado como ocurrido en el ámbito de la Escuela de Mecánica de la Armada (ESMA) y que ha sido calificado como histórico 'ya que por vez primera se admitió en los tribunales argentinos un amicus curiae', según afirma el profesor Víctor Bazán”.

Se añaden otros casos que dan plena vigencia al amicus curiae en dicho país, como son los de "Sterla, Silvia s/ interrupción de la prisión preventiva", "Mignora, Emilio Fermín s/ promueve acción de amparo", entre otros. ${ }^{30}$ 
El caso más llamativo lo constituye el conocido por el Tribunal Penal Internacional para la ex Yugoslavia, cuya norma 74 de las Reglas de Procedimiento consagra el derecho de los interesados, cualesquiera sea su condición, para presentarse a juicio vía amicus curiae, sin necesidad de mayor requisito.

El Tribunal Europeo de Derechos Humanos, la Comisión y la Corte Internacional de Derechos Humanos también contemplan al amicus curiae, en los artículos 36, 62.3 y 44.3 de las normas aplicables respectivamente en los organismos citados. ${ }^{31}$

Debemos, por último, considerar el desarrollo que ha tenido en el campo de las diferencias constitucionales y su resolución jurídica observada fundamentalmente en Argentina y Brasil, como lo explican los profesores Víctor Bazán ya citado, Gustavo Fontana Pedrollo, ${ }^{32}$ Milton Luis Pereira y otros más. ${ }^{33}$

Seguramente ante el incremento de casos que se presentarán en los foros ya señalados y en otros más, los estudios analíticos también proliferarán.

\section{CONCLUSIÓN Y SUGERENCIAS}

Adicionalmente a lo ya consignado en nuestras reflexiones, podemos concluir el presente estudio, diciendo que:

1. El amicus curiae responde a una necesidad básica que está presente en el debido proceso, consistente en la garantía de audiencia.

2. Por lo tanto, su naturaleza jurídica es de un derecho subjetivo que debe ser reconocido por las legislaciones normativas de todo proceso legal.

3. El titular de dicha facultad subjetiva es cualquier persona física o moral que considere legítimamente que puede verse afectada por el resultado de un procedimiento contencioso y que no tenga el carácter de parte o de tercero.

31 Véase Trocher, Nicoló, op. cit.

32 "Amicus Curiae. Elemento de participação política nas decisões judiciais-constitucionais", Revista A Júris, Porto Alegre, año XXXII, septiembre de 2005.

33 “Amicus Curiae: Intervenção de terceiros", Revista CEJ, Brasília, año VI, septiembre de 2002 . 
4. La vía procesal idónea es la institución del amicus curiae, en la versión definida consignada en el presente estudio acorde con la práctica observada en los foros contenciosos establecidos de conformidad con el ESD de la OMC.

5. El obligado frente al derecho subjetivo, que sustenta la facultad de audiencia que existe todo proceso legal que se viene ejerciendo a través del amicus curiae, será el tribunal específico que conozca de una diferencia de intereses acorde con el Anexo 2 de la OMC.

6. Por lo expuesto, se debe instar a la OMC para que formalice a la brevedad la institución, reformando en lo conducente las normas y procedimientos que rigen la solución de diferencias contenidas en el Anexo 2 de los acuerdos multilaterales que lo componen. 